\title{
Montesquieu, Correspondance choisie. «Avec respect et l'amitié la plus tendre»
}

\section{Eszter Kovács}

\section{(2) OpenEdition}

1 Journals

\section{Édition électronique}

URL : http://journals.openedition.org/studifrancesi/9956

DOI : 10.4000/studifrancesi.9956

ISSN : 2421-5856

Éditeur

Rosenberg \& Sellier

\section{Édition imprimée}

Date de publication : 1 août 2017

Pagination : 359-360

ISSN : 0039-2944

\section{Référence électronique}

Eszter Kovács, « Montesquieu, Correspondance choisie. "Avec respect et l'amitié la plus tendre» », Studi Francesi [En ligne], 182 (LXI | II) | 2017, mis en ligne le 01 août 2017, consulté le 07 janvier 2021. URL : http://journals.openedition.org/studifrancesi/9956 ; DOI : https://doi.org/10.4000/studifrancesi.9956

Ce document a été généré automatiquement le 7 janvier 2021.

\section{(c) $(1) \&$}

Studi Francesi è distribuita con Licenza Creative Commons Attribuzione - Non commerciale - Non opere derivate 4.0 Internazionale. 


\title{
Montesquieu, Correspondance choisie. «Avec respect et l'amitié la plus tendre»
}

\author{
Eszter Kovács
}

\section{RÉFÉRENCE}

MONTESQUIEU, Correspondance choisie. «Avec respect et l'amitié la plus tendre», éd. Philip STEWART, Paris, Classiques Garnier, 2015, «Correspondances et Mémoires» 24, 284 pp.

1 Le premier tome de l'édition critique de la Correspondance de Montesquieu a paru en 1998 (Euvres complètes, tome 18), sous la direction du regretté Louis Desgraves et d'Edgar Mass. Le deuxième (Euvres complètes, tome 19) a paru en 2014 sous la direction de Philip Stewart et de Catherine Volpilhac-Auger (je m'excuserai de ne pas pouvoir mentionner les noms de tous les collaborateurs dans ce bref compte rendu). Il reste encore deux volumes de la Correspondance et il serait inutile d'insister sur l'effort que demande ce travail collectif. En attendant, Philip Stewart offre au public une Correspondance choisie. Le texte des lettres est modernisé, ce qui est absolument justifié en cas d'un choix de textes destiné au public avant la parution des volumes restants de l'édition critique. Le volume ne décourage nullement ceux qui ne sont pas des spécialistes de Montesquieu, mais peut également être utile à ceux qui le sont. Bien que l'édition d'un choix de lettres ne puisse pas être considérée un outil de recherche au même titre que l'édition critique de la Correspondance complète, il sert parfaitement comme un "guide" pour les étudiants, les jeunes chercheurs et les enseignants dixhuitiémistes.

2 Dans l'introduction, l'éditeur nous donne un aperçu biographique et présente le réseau de correspondants du Président. Comme il le précise, il cherche à dégager Montesquieu (l'auteur mais aussi l'homme) de l'image d'austérité et de gravité qui l'entoure. Son objectif est de présenter la variété thématique ainsi que les nuances stylistiques des lettres et, par là, les aspects moins connus de la vie et de l'œuvre de Montesquieu. L'histoire éditoriale de cette Correspondance mérite également notre attention: elle se 
compose de moins de 1000 lettres conservées, dont certaines existent sous forme de copie ou de brouillon. La plus grande partie de la Correspondance est dite «active» mais il serait problématique de considérer le manuscrit existant comme une vraie missive dans certains cas. Les copies et brouillons laissent les spécialistes dans l'incertitude: ces lettres ont-elles été réellement envoyées et si oui, sous quelle forme? Certaines lettres sont autographes, d'autres sont de la main d'un secrétaire. Mais ce qui en rend l'édition encore plus difficile, c'est le fait que la Correspondance de Montesquieu est dispersée aujourd'hui. Les spécialistes ne peuvent pas toujours avoir accès au manuscrit original et le retranscrire, il faut donc avoir recours dans bien des cas aux sources imprimées, c'est-à-dire aux éditions antérieures, dont la première, contenant les lettres dites «familières» à des amis italiens, a paru en 1767. Philip Stewart présente soigneusement ces sources dans son introduction et signale à la fin des lettres la source imprimée ou le lieu de conservation du manuscrit.

Le volume contient des lettres intégrales, approximativement un cinquième des lettres conservées. Parmi les correspondants, on trouve les membres de la famille de Montesquieu, des aristocrates, des ecclésiastiques, des salonnières, des savants et des philosophes. Certains noms sont très connus, comme celui de Mme de Tencin, d'Helvétius, de La Condamine, de Hume, etc. La variété des sujets est également remarquable: dans la Lettre 38, de Mme de Tencin à Montesquieu, il s'agit du fameux vin de Tokay, la lettre 30 est une lettre d'amour à la princesse Trivulzio. La lettre 160, écrite à D'Alembert en 1753, concerne l'Encyclopédie: Montesquieu ne se charge pas des articles DÉMOCRATIE et DESPOTISME, il préfère l'article goût (le fait est connu mais le lecteur le voit confirmé par Montesquieu lui-même). Plusieurs lettres concernent le destin de L'Esprit des lois après sa parution en 1748.

L'apparat critique est de qualité. L'introduction, d'une douzaine de pages, peut toutefois nous paraître un peu modeste par rapport à la complexité de la tâche éditoriale. Les notes servent la mise en contexte historique et permettent de situer les allusions biographiques, autant que possible. Un certain nombre de notes éclairent les intertextes (citations ou paraphrases) ou concernent le lexique. On trouve à la fin du volume la liste chronologique des lettres, une brève chronologie de la vie et des œuvres de Montesquieu et l'index des noms de personnes, toujours très utile sinon indispensable dans une correspondance. Il aurait peut-être été utile d'intégrer une notice bibliographique contenant les études les plus importantes consacrées à la Correspondance de Montesquieu, mais on dispose de tous les repères nécessaires pour lire les lettres choisies et de se former une idée de Montesquieu épistolier. Je voudrais signaler un avantage non négligeable d'une telle édition: à l'encontre des volumes prestigieux des Euvres complètes, il est tout à fait abordable pour une bibliothèque personnelle. 